\title{
System of Mueller matrix polarization correlometry of biological polycrystalline layers
}

V. O. Ushenko, O. Vanchuliak, M. Yu. Sakhnovskiy, O. V. Dubolazov, P. Grygoryshyn, et al.

V. O. Ushenko, O. Vanchuliak, M. Yu. Sakhnovskiy, O. V. Dubolazov, P. Grygoryshyn, I. V. Soltys, O. V. Olar, "System of Mueller matrix polarization correlometry of biological polycrystalline layers," Proc. SPIE 10352, Biosensing and Nanomedicine X, 103520 U (29 August 2017); doi: $10.1117 / 12.2273789$

SPIE Event: SPIE Nanoscience + Engineering, 2017, San Diego, California, United States 


\title{
System of Mueller matrix polarization correlometry of biological polycrystalline layers
}

\author{
V.O. Ushenko ${ }^{a}$, O.Vanchuliak ${ }^{\mathrm{b}}$, M.Yu. Sakhnovskiy ${ }^{\mathrm{a}}$, O.V. Dubolazov ${ }^{\mathrm{a}}$, \\ P. Grygoryshyn , I.V. Soltys ${ }^{\mathrm{a}}$, O.V. Olar ${ }^{\mathrm{a}}$ \\ ${ }^{a}$ Chernivtsi National University, 2 Kotsyubinsky Str., Chernivtsi, 58012, Ukraine \\ ${ }^{\mathrm{b}}$ Bukovinian State Medical University, Chernivtsi, 58000, Ukraine
}

\begin{abstract}
The model of the azimuthally invariant Mueller-matrix description of polarization-correlation mechanisms of optical anisotropy that typical for polycrystalline layers of the histological sections of biological tissues is suggested. Within the statistical analysis of the ranges of linear and circular birefringence, dichroism, the objective criteria for the differentiation of myocardium histological sections were determined. From the point of view of probative medicine the ranges of variation of the statistical parameters that characterize the Mueller-matrix invariants of optical anisotropy parameters were found.
\end{abstract}

Keywords: polarimetry, Mueller matrix, polycrystalline film, laser image, biological tissues and fluids. a.dubolazov@.chnu.edu.ua

\section{INTRODUCTION}

The theoretical basics of the Mueller-matrix polarimetry of optically anisotropic biological layers are fully described in ${ }^{1-}$ ${ }^{9}$. The development of these techniques has become the methods of laser polarimetry ${ }^{10-16}$.

A new step in the clinical applications of Mueller-matrix formalism was using of azimuthal polarization invariants to describe differentiations in the correlation manifestations of changes in phase shifts between the orthogonal components of the amplitude of laser radiation.

- This research is focused on the further development of azimuthally invariant Mueller-matrix mapping of the histological sections of myocardium tissue in tasks of differentiating necrotic changes in fibrillar networks. The relevance of this study is substantiated in ${ }^{17-23}$.

\section{BRIEF THEORETICAL BACKGROUND}

The basis of our work is based on modeling representations of the phase (circular and linear birefringence) and amplitude (circular and linear dichroism) of anisotropy of the polycrystalline structure of the biological layers.

To describe the polarization-correlation manifestations of the optical anisotropy of biological tissues we propose the following Mueller-matrix invariants:

- Elements of Mueller Matrix

$$
M_{11} ; \quad M_{14} ; \quad M_{41} ; \quad M_{44}
$$

- Combinations of Mueller matrix elements

$$
\begin{aligned}
& \Sigma \equiv\left(M_{22}+M_{33}\right) ; \\
& \aleph \equiv\left(M_{23}-M_{32}\right) .
\end{aligned}
$$

Biosensing and Nanomedicine X, edited by Hooman Mohseni, Massoud H. Agahi, Manijeh Razeghi, Proc. of SPIE Vol. 10352, 103520U · (c) 2017 SPIE · CCC code: 0277-786X/17/\$18 · doi: 10.1117/12.2273789 
- Lengths of mathematical vectors

$$
\left\{\begin{array}{l}
A_{h}=\sqrt{M_{12}^{2}+M_{13}^{2}} \\
A_{V}=\sqrt{M_{21}^{2}+M_{31}^{2}} \\
B_{h}=\sqrt{M_{42}^{2}+M_{43}^{2}} \\
B_{V}=\sqrt{M_{24}^{2}+M_{34}^{2}}
\end{array}\right.
$$

- Angles

$$
\begin{aligned}
& \cos \left(B_{h}, B_{V}\right)=\frac{-\sqrt{\left(M_{42}^{2}+M_{43}^{2}\right)}}{\sqrt{\left(M_{24}^{2}+M_{34}^{2}\right)}} . \\
& \left\{\begin{array}{l}
\left\{A_{h}\right\}=\frac{1}{\sqrt{M_{12}^{2}+M_{13}^{2}}}\left(\begin{array}{l}
M_{12}^{2}-M_{13}^{2} \\
2 M_{12} M_{13}
\end{array}\right) ; \\
\left\{A_{V}\right\}=\frac{1}{\sqrt{M_{21}^{2}+M_{31}^{2}}}\left(\begin{array}{l}
M_{21}^{2}-M_{31}^{2} \\
2 M_{21} M_{31}
\end{array}\right) ; \\
\left\{B_{h}\right\}=\frac{1}{\sqrt{M_{42}^{2}+M_{43}^{2}}}\left(\begin{array}{l}
M_{42}^{2}-M_{43}^{2} \\
2 M_{42} M_{43}
\end{array}\right) ; \\
\left\{B_{V}\right\}=\frac{1}{\sqrt{M_{24}^{2}+M_{34}^{2}}}\left(\begin{array}{l}
M_{24}^{2}-M_{34}^{2} \\
2 M_{24} M_{34}
\end{array}\right)
\end{array},\right. \\
& G=\sqrt{\left(M_{22}-M_{33}\right)^{2}+\left(M_{23}-M_{32}\right)^{2}} .
\end{aligned}
$$

Using the set of MMI will provide conditions for using of the methods of experimentally reconstruction of Muellermatrix mapping on serial, screening studies of biological tissues samples of human organs in various biomedical diagnostic tasks.

\section{THE TECHNIQUE OF EXPERIMENT}

The measurements of coordinate distributions of Mueller-matrix elements (distribution of values in the film plane of bile) were performed in the setup of the conventional Stokes-polarimeter ${ }^{10}$.

A set of statistical moments of the $1^{\text {st }}-4^{\text {th }}$ orders characterizing distributions $q$ was calculated using the algorithms

$$
Z_{1}=\frac{1}{N} \sum_{j=1}^{N}|q| ; Z_{2}=\sqrt{\frac{1}{N} \sum_{j=1}^{N}\left(q-Z_{1}\right)_{j}{ }^{2}} ; Z_{3}=\frac{1}{Z_{2}{ }^{3}} \frac{1}{N} \sum_{j=1}^{N}\left(q-Z_{1}\right)_{j}^{3} ; Z_{4}=\frac{1}{Z_{2}{ }^{4}} \frac{1}{N} \sum_{j=1}^{N}\left(q-Z_{1}\right)_{j}{ }^{4}
$$

$N$ - the number of pixels of CCD-camera. 


\section{AZIMUTALLY-INVARIANT MULLER MATRIX IMAGES}

In fig. 1 and fig. 2 are shown maps and histograms of distribution of the following values of MMI:

- matrix element (fragments (1), (2), ratio (1));

- combinations of matrix elements (fragments (3) - (8), ratio (2) - (3));

- lengths of matrix vectors (fragments (9) - (16), ratio (4));

- matrix angles (fragments (17) - (18), relations (5) - (7)),

which characterize the phase anisotropy (linear and circular birefringence) of the partially depolarizing layers of the histological sections of the myocardium tissue (Fig. 1) and the brain (Fig. 2).

The purpose of azimuthally invariant mapping of polycrystalline networks of optically thick biological layers was to determine the most sensitive to changes in the phase anisotropy of Muller-matrix invariants, as well as the corresponding values of the set of statistical moments of the 1st-4th orders corresponding to their distributions, - Table 1 (histological section of myocardium tissue).

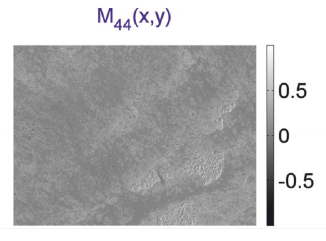

(1)

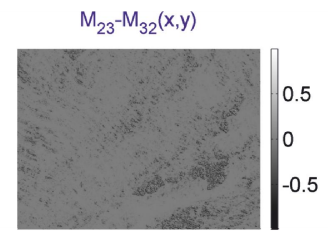

(5)

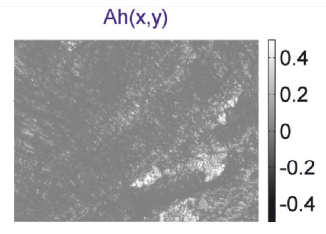

(9)

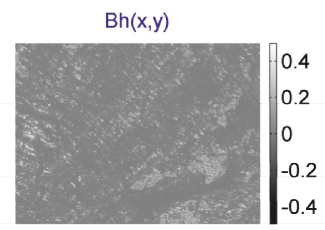

(13)

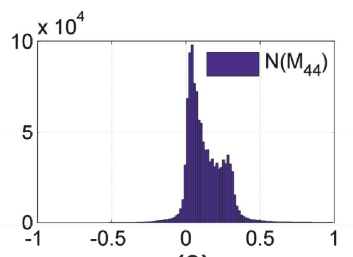

(2)

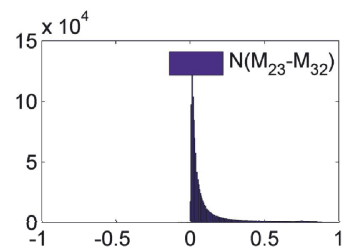

(6)

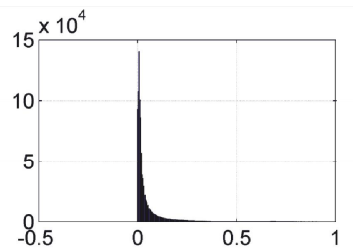

(10)

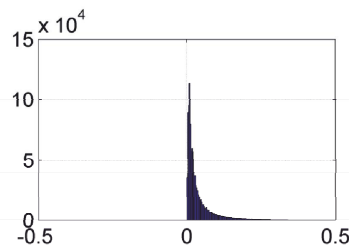

(14)

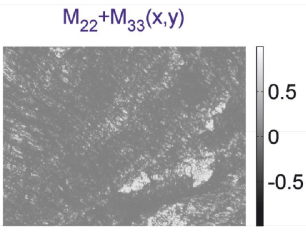

(3)

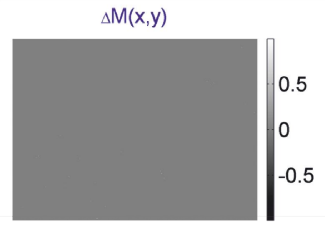

(7)

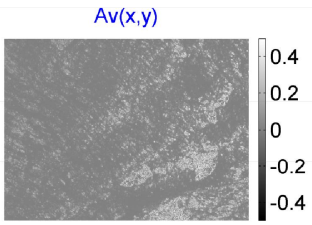

(11)

$\operatorname{Bv}(x, y)$

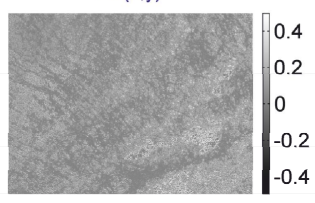

(15)

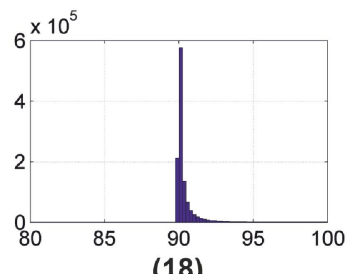

(18)

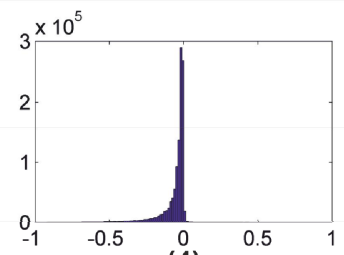

(4)

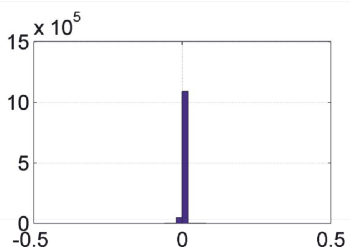

(8)

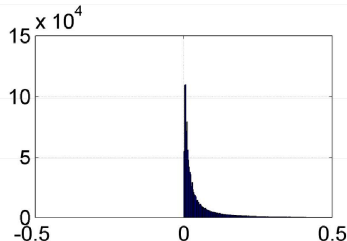

(12)

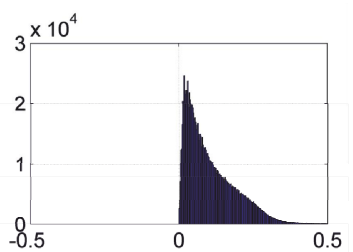

(16)

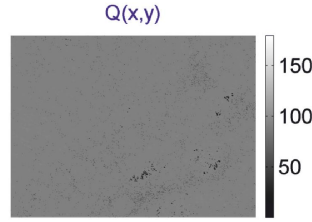

(17)

Fig. 1. Maps and histograms for the distribution of MMI of the optically-thick histological sections of myocardium tissue. 


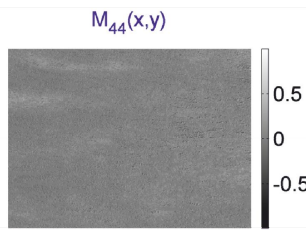

(1)

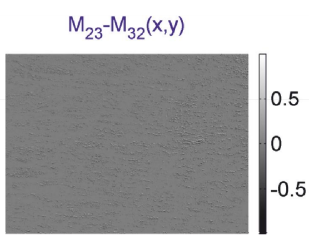

(5)

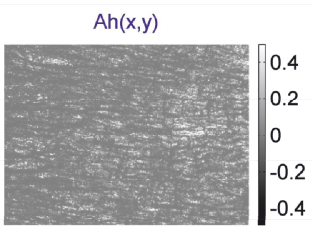

(9)

$\operatorname{Bh}(x, y)$

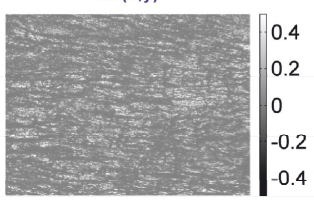

(13)

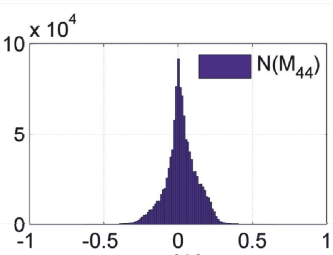

(2)

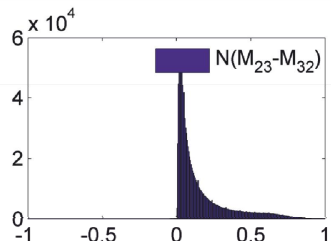

(6)

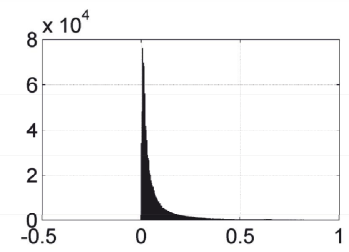

(10)

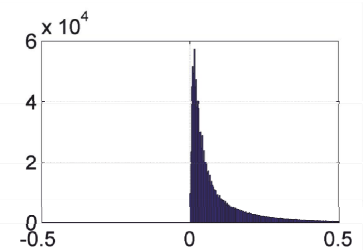

(14)

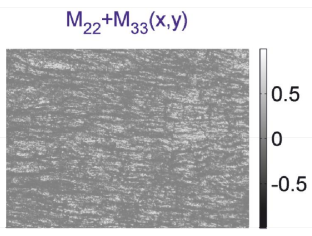

(3)

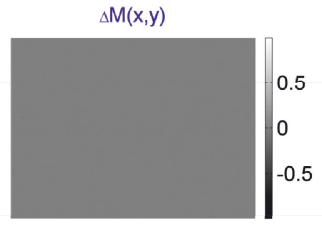

(7)

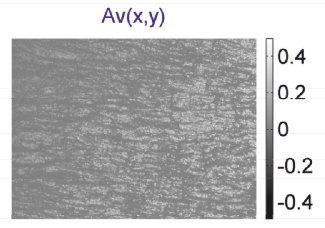

(11)

$\mathrm{Bv}(\mathrm{x}, \mathrm{y})$

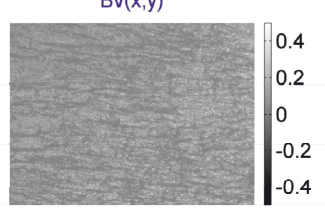

(15)

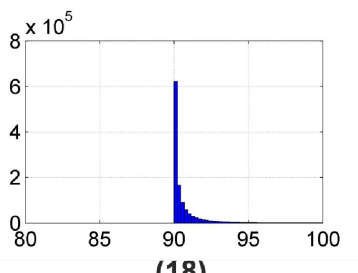

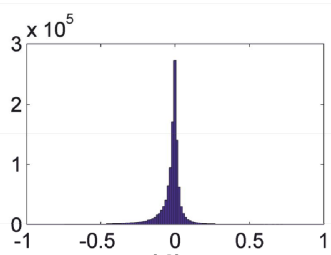

(4)

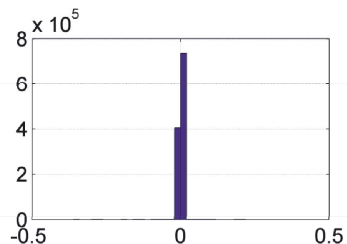

(8)

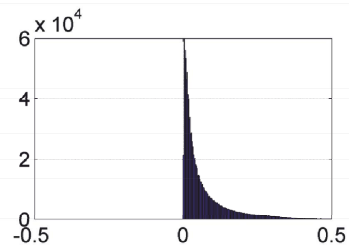

(12)

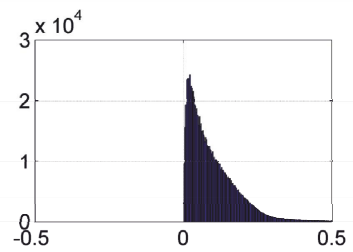

(16)

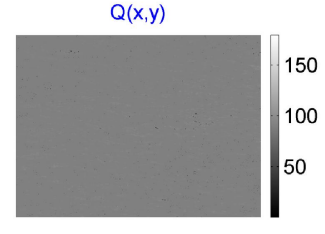

(17)

(18)

Fig. 2. Maps and histograms for the distribution of MMI of the optically-thick histological sections of brain tissue.

Analysis of the results of azimuthally invariant Mueller-matrix mapping of optically thick, partially depolarizing layers of different morphological structures biological tissues revealed the sensitivity of MMI to the distribution of linear and circular birefringence of biological tissues of various organs ("matrix vectors" $A_{h} ; A_{v} ; B_{h}$; "combinations of matrix elements" $M_{22}+M_{33} ; M_{23}-M_{32}$; "matrix elements" $M_{44}$; "matrix angles" - $\left\{B_{v}\right\} ; G$;). Quantitatively, this fact illustrates a sufficiently wide range of non-zero (except for a "combination of matrix elements") values of all MMI-maps which are shown on fig. 1 and fig. 2. 
Table 1.Statistical moments of the 1 st - 4 th orders, which characterize the distributions of the mean values of opticallythick histological section of myocardium tissue

\begin{tabular}{|c|c|c|c|c|c|c|c|c|c|}
\hline$Z_{i}$ & $A_{h}$ & $A_{v}$ & $B_{h}$ & $\Delta M$ & $M_{22}+M_{33}$ & $M_{23}-M_{32}$ & $M_{44}$ & $\left\{B_{v}\right\}$ & $Q$ \\
\hline$Z_{1}$ & 0,04 & 0,05 & 0,04 & 0,001 & 0,11 & 0,06 & 0,13 & 0,04 & 89,63 \\
\hline$Z_{2}$ & 0,08 & 0,07 & 0,05 & 0,001 & 0,16 & 0,12 & 0,12 & 0,07 & 63,88 \\
\hline$Z_{3}$ & 4,06 & 5,11 & 3,11 & 148 & 2,77 & 3,14 & 0,93 & 3,56 & 11,27 \\
\hline$Z_{4}$ & 21,5 & 11,03 & 12,6 & 1239 & 7,83 & 13,5 & 2,57 & 18,3 & 120,9 \\
\hline
\end{tabular}

\section{CONCLUSIONS}

1. The Mueller-matrix model of generalized phase and amplitude anisotropy of polycrystalline networks of biological tissues of human organs is elaborated.

2. It has been proposed the new method of mapping of histological sections of biological tissues by means of measuring the coordinate distributions of values of the set of Mueller-matrix invariants.

3. The Muller-matrix invariants most sensitive to the peculiarities of optical anisotropy of myocardial fibrillar networks have been identified.

\section{REFERENCES}

[1] T. T. Tower, R. T. Tranquillo, "Alignment Maps of Tissues: I. Microscopic Elliptical Polarimetry," Biophys. J. 81, 2954$2963(2001)$.

[2] J. M. Bueno, J. Jaronski, "Spatially resolved polarization properties for in vitro corneas," Ophthal. Physiol. Opt. 21, 384-392 (2001).

[3] M. H. Smith, "Interpreting Mueller matrix images of tissues," Proc.SPIE 4257, 82-89 (2001).

[4] M. H. Smith, P. Burke, A. Lompado, E. Tanner, L. W. Hillman, "Mueller matrix imaging polarimetry in dermatology," Proc.SPIE.3991, 210-216 (2000).

[5] J. M. Bueno, F. Vargas-Martin, "Measurements of the corneal birefringence with a liquid-crystal imaging polariscope," Applied Optics 41, 116-124 (2002).

[6] T. T. Tower, R. T.Tranquillo, "Alignment Maps of Tissues: II. Fast Harmonic Analysis for Imaging," Biophys. J. 81, 29642971 (2001).

[7] M. Shribak and R. Oldenbourg, "Techniques for Fast and Sensitive Measurements of Two-Dimensional Birefringence Distributions," Appl. Opt. 42, 3009-3017 (2003).

[8] Angelsky, O. V., Gorsky, M. P., Hanson, S. G., Lukin, V. P., Mokhun, I. I., Polyanskii, P. V., Ryabiy, P. A., "Optical correlation algorithm for reconstructing phase skeleton of complex optical fields for solving the phase problem," Opt. Exp. 22(5), 6186-6193 (2014).

[9] Lu, R. A. Chipman "Interpretation of Mueller matrices based on polar decomposition," J. Opt. Soc. Am. A 13, 1106-1113 (1996).

[10] A. G. Ushenko and V. P. Pishak, "Laser Polarimetry of Biological Tissue: Principles and Applications", in Handbook of Coherent-Domain Optical Methods: Biomedical Diagnostics, Environmental and Material Science, Vol. 1, pp. 93-138, edited by Valery V. Tuchin, Kluwer Academic Publishers (2004).

[11] Yu. A. Ushenko, T. M. Boychuk, V. T. Bachynsky, O. P. Mincer, "Diagnostics of Structure and Physiological State of Birefringent Biological Tissues: Statistical, Correlation and Topological Approaches" in Handbook of Coherent-Domain Optical Methods, Springer Science+Business Media, p. 107, New York (2013).

[12] O. V. Angelsky, A. G. Ushenko, Yu. A. Ushenko, Ye. G. Ushenko, "Polarization singularities of the object field of skin surface,” J. Phys. D: Appl. Phys. 39, 3547 -3558 (2006).

[13] V. A. Ushenko, M. P. Gorsky, "Complex degree of mutual anisotropy of linear birefringence and optical activity of biological tissues in diagnostics of prostate cancer," Optics and Spectroscopy, 115(2), 290-297 (2013). 
[14] Yu. A. Ushenko, M. P. Gorskii, A. V. Dubolazov, A. V. Motrich, V. A. Ushenko, M. I. Sidor "Spatial-frequency Fourier polarimetry of the complex degree of mutual anisotropy of linear and circular birefringence in the diagnostics of oncological changes in morphological structure of biological tissues," Quantum Electron, 42(8) 2012.

[15] O. V. Angelsky, Yu. Ya. Tomka, A. G. Ushenko, Ye. G. Ushenko, Yu. A. Ushenko, "Investigation of 2D Mueller matrix structure of biological tissues for preclinical diagnostics of their pathological states," J. Phys. D: Appl. Phys. 38, 4227-4235 (2005).

[16] L. V. Kakturskiǐ, "Clinical morphology of acute coronary syndrome," Arkh Patol. 69, 16-19 (2007).

[17] Cristina Basso, Fiorella Calabrese, Domenico Corrado, Gaetano Thiene, "Postmortem diagnosis in sudden cardiac death victims: macroscopic, microscopic and molecular findings," Cardiovascular Research 50, 290-300 (2001).

[18] M.D. Pérez-Cárceles, J. Noguera, J.L. Jiménez, P. Martínez, A. Luna, E. Osuna, "Diagnostic efficacy of biochemical markers in diagnosis post-mortem of ischaemic heart disease," Forensic Science International 142, 1-7 (2004).

[19] F. Martínez Díaz, M. Rodríguez-Morlensín, M.D. Pérez-Cárceles, J. Noguera, A. Luna and E. Osuna, "Biochemical analysis and immunohistochemical determination of cardiac troponin for the postmortem diagnosis of myocardial damage," Histol. Histopathol. 20, 475-481 (2005).

[20] L. D. Cassidy, "Basic concepts of statistical analysis for surgical research," Journal of Surgical Research 128,199-206 (2005).

[21] C. S. Davis, Statistical methods of the analysis of repeated measurements, p. 744New York: Springer-Verlag, 2002.

[22] A. Petrie, B. Sabin, Medical Statistics at a Glance: p. 157, Blackwell Publishing (2005).

[23] M. Dugum, A. McCullough Diagnosis and Management of Alcoholic Liver Disease. J Clin Transl Hepatol.. 28;3(2), 109-116 (2015)

[24] D. E. Kleiner, E. M. Brunt "Nonalcoholic fatty liver disease: pathologic patterns and biopsy evaluation in clinical research," Semin Liver Dis. 32(1), 3-13 (2012).

[25] van Beek D., Funaki B. "Hemorrhageas a complication of percutaneous liver biopsy," Semin Intervent Radiol. Dec 30(4), 413$6(2013)$

[26] A. A. Bravo, S. G. Sheth, S. Chopra Liver biopsy. N Engl J Med. 344, 495-500 (2001).

[27] N. Boute, O. Gribouval, S. Roselli et al. NPHS2, "Encoding the glomerular protein podocin, is mutated in autosomal recessive steroid-resistant nephrotic syndrome," Nat Genet; 24(4), 349-54 (2000).

[28] Y. T. Chen, A. Kobayashi, K.M. Kwan et al. Gene expression profiles in developing nephrons using Lim1 metanephric mesenchyme-specific conditional mutant mice. BMC Nephrol (2006).

[29] P. N. Hawkins. "Serum amyloid P component scintigraphy for diagnosis and monitoring amyloidosis," Curr Opin Nephrol Hypertens 11, 649-655 (2002).

[30] B. G, Hudson, K. Tryggvason, M. Sundaramoorthy, E.G. Neilson. “Alport's syndrome, Goodpasture's syndrome, and type IV collagen," N Engl J Med 348, 2543-2556 (2003).

[31] L. Rampoldi, F. Scolari, A. Amoroso et al. "The rediscovery of uromodulin (Tamm-Horsfall protein): from tubulointerstitial nephropathy to chronic kidney disease,” Kidney International, 80, 338-347 (2011).

[32] K. Tryggvason, J. Patrakka, J. Wartiovaara, "Hereditary Proteinuria Syndromes and Mechanisms of Proteinuria," N Engl J Med 354, 1387-1401 (2006).

[33] H. Joachim, U. Feldmann "Quantimetric investigations of the time of death by estimating the postmortem threshold (rheobase) of human skeletal muscles to electric stimulus by direct current (author's transl)," Z. Rechtsmed. 85(1), 5-22 (1980).

[34] Shimizu, T. Hayashi, Y. Saitoh [et al.], "Postmortem autolysis in the pancreas: multivariate statistical study. The influence of clinicopathological conditions," Pancreas. 5(1), 91-94 (1990).

[35] F. Kuroda, K. Hiraiwa, S. Oshida [et al.], "Estimation of postmortem interval from rectal temperature by use of computer (III)thermal conductivity of the skin," Med. Sci. Law. 22(4), 285-289 (1982).

[36] F. Brion, B. Marc, F. Launay, "Postmortem interval estimation by creatinine levels in human psoas Muscle," Forensic Sci. Int. 52(1), 113-120 (1991).

[37] L. D. Cassidy, "Basic concepts of statistical analysis for surgical research," Journal of Surgical Research 128,199-206 (2005).

[38] C. S. Davis, [Statistical methods of the analysis of repeated measurements], p. 744New York: Springer-Verlag, 2002. 